\title{
Clinical Trials in Parkinson's Disease Dementia and Dementia with Lewy Bodies
}

\author{
Richard Camicioli, Serge Gauthier
}

\begin{abstract}
Parkinson's disease with dementia (PDD) and dementia with Lewy bodies (DLB) are pathological overlapping and important causes of dementia for which clinical trials are in their infancy. Cholinesterase inhibitors may be of benefit in DLB and PDD, as suggested by placebo-controlled clinical trials of rivastigmine and donepezil. The anti-psychotic agent clozapine has been of benefit in PD and PDD, but other agents, such as quetiapine, require adequate assessment. Barriers to trials include pathological overlap that can lead to inaccuracies in clinical diagnosis, unavailability of a consensus definition for PDD, unanswered questions regarding natural history and the paucity of validated outcome measures. Motor impairment must be considered in patients with PDD and DLB; conversely, cognitive impairment should be assessed in trials targeting motor impairment in advanced PD. Potential targets for treatment include onset of dementia, cognitive impairment, behavioral impairment, functional decline, falls, nursing home placement, mortality, quality of life and economic impact. Biomarkers including neuroimaging and cerebrospinal fluid markers are not currently established. At present PDD and DLB are distinct entities by definition. Future studies, including clinical trials and biomarker studies, will help to further define the clinical and therapeutic implications of this distinction.
\end{abstract}

RÉSUMÉ: Essais cliniques sur la démence de la maladie de Parkinson et la démence à corps de Lewy. La maladie de Parkinson avec démence (MPD) et la démence à corps de Lewy (DCL) sont des causes importantes de démence qui se chevauchent au point de vue pathologique. Les essais cliniques sur ces deux types de démence en sont au tout début. Selon des essais cliniques contrôlés par placebo portant sur la rivastigmine et le donépézil, les inhibiteurs de la cholinestérase pourraient être bénéfiques dans la DCL et la MPD. Les patients atteints de MP et de MPD ont tiré un bénéfice du traitement par la clozapine, un anti-psychotique, mais d'autres agents tels la quétiapine n'ont pas été évalués adéquatement. Plusieurs obstacles devront être surmontés, notamment le chevauchement des pathologies qui peut entraîner des erreurs diagnostiques, le manque de consensus sur la définition de la MPD, des questions non résolues concernant leur évolution naturelle et le manque de critères d'évaluation validés. Chez les patients atteints de MPD et de DCL, on doit tenir compte de l'atteinte motrice et dans la MPD en phase avancée, l'atteinte cognitive devrait être évaluée au cours d'essais cliniques ciblant l'atteinte motrice. Le début de la démence, l'atteinte cognitive, l'atteinte comportementale, le déclin fonctionnel, les chutes, le placement en établissement de soins prolongés, la mortalité, la qualité de vie et l'impact économique sont des cibles pour l'évaluation du traitement. Les biomarqueurs tels les marqueurs de neuro-imagerie et ceux du liquide céphalorachidien ne sont pas validés. Pour l'instant, la MPD et la DCL sont des entités distinctes par définition. D'autres études, en particulier des essais cliniques et des études de biomarqueurs aideront à mieux définir les implications cliniques et thérapeutiques de cette distinction.

Can. J. Neurol. Sci. 2007; 34: Suppl. 1 - S109-117

Parkinson's disease with dementia (PDD) and dementia with Lewy bodies (DLB) are common causes of dementia with overlapping pathological features of alpha-synuclein staining sub-cortical and cortical Lewy bodies, and co-existent Alzheimer disease (AD) pathology in some cases (Table 1). ${ }^{1}$ Distinguishing clinical features include the timing of onset of parkinsonism and dementia. Parkinsonism precedes dementia by at least one year for PDD, but occurs within 12 months of each other in DLB. Consensus criteria for DLB (dementia with parkinsonism, hallucinations and cognitive fluctuations) are available, ${ }^{2}$ and have recently been revised in order to improve sensitivity and specificity. The revised criteria acknowledge challenges in timing the onset of motor and cognitive difficulties, and include suggestive features such as REM sleep behavior disorders, neuroleptic sensitivity and decreased striatal dopamine transporter binding. ${ }^{3}$ As currently applied, diagnostic criteria for DLB are specific but not sensitive, though assessment for visuospatial dysfunction and other features may improve sensitivity. ${ }^{4}$ Criteria are in development for PDD. Currently generic criteria for dementia such as DSM-IV or ICD-10 criteria are applied to diagnose PDD. ${ }^{5}$ Parkinson's disease onset should

From the Glenrose Rehabilitation Hospital (RC), Edmonton, AB; Alzheimer Disease Research Unit, McGill Centre for Studies in Aging (SG), Verdun, QC, Canada. RECEIVED OCTOBER 7, 2005. ACCEPTED IN FINAL FORM MAY 9, 2006.

Reprint requests to: Richard Camicioli, E223, Glenrose Rehabilitation Hospital, 10230 - 111th Avenue, Edmonton, Alberta, T5G 0B7, Canada. 


\section{Table 1: Pathological and neurochemical features of Parkinson's disease with dementia and Dementia with Lewy bodies}

Cortical Lewy bodies
Mesolimbic Lewy bodies
Co-existent pathology
Alzheimer's Disease
Vascular
Neurotransmitter system changes
$\quad$ Dopamine, noradrenaline, acetylcholine, serotonin,
glutamate, gamma-aminobutyric acid

be well established before the diagnosis of dementia, but at a minimum should precede the diagnosis by at least one year to avoid overlap with DLB; in general, parkinsonism will precede dementia for a longer period. Definitions of PDD should recognize that while memory may be impaired, non-amnestic features can be prominently affected (e.g., impaired attention/fluctuations, executive function/working memory, verbal fluency, visuospatial function). Behavioral symptoms such as apathy, depression, psychosis and personality change may also be prominent. Currently it is recommended that DSMIV criteria be used, but that non-memory domains be given equal weighting to memory. It is likely that subtypes of PDD exist (amnestic, dysexecutive, mixed, DLB-like) but require validation. As is the case for other dementias, potential target domains for clinical trials include progression to dementia (e.g., conversion rate), cognitive dysfunction (especially executive dysfunction), behavioral and psychiatric problems (e.g., depression and psychosis), functional status (e.g., Activities of daily living (ADLs) and instrumental activities of daily living (IADLs)), global impairment and quality of life, among other domains (Table 2). In addition to symptomatic therapies, disease modifying treatments are likely to be developed in the future. Motor symptoms of parkinsonism represent an added dimension that requires specific investigation and monitoring in clinical trials, ${ }^{6}$ as do sleep disorders, which are also common in synucleinopathies. ${ }^{7}$ Practice parameters for assessment and management of behavioral problems in PD have been put forward. ${ }^{8}$

\section{Neuropsychological Features}

Both PDD and DLB patients can exhibit greater executive dysfunction and cognitive slowing with less severe episodic memory impairment than $\mathrm{AD},{ }^{9-12}$ making existing paradigms and criteria that emphasize memory as a primary criterion for dementia imperfect. Visuospatial deficits are prominent in $\mathrm{DLB}^{13}$ whereas semantic memory may be equally affected in DLB and AD. ${ }^{14}$ Whether a group of patients with mild cognitive impairment (e.g., amnestic, executive, multi-domain), without

\section{Table 2: Targets of treatments}

\author{
Cognitive impairment \\ Behavioral impairment \\ Motor function \\ Functional impairment \\ Global outcomes \\ Onset of dementia \\ Caregiver burden \\ Quality of Life \\ Sleep disorder \\ Falls \\ Hospitalization \\ Nursing home placement \\ End of life care \\ Mortality \\ Economic impact
}

functional impairment, can be defined by analogy to the elderly who progress to Alzheimer disease remains to be established. ${ }^{15}$ Studies that target specific subgroups or target symptoms may be relevant. Treatment response in various cognitive domains may differ.

Dementia with Lewy Bodies is characterized by fluctuating attention and visuo-spatial impairment. The few studies which directly compare PDD and DLB with respect to cognitive profile mostly show overlap. ${ }^{10,16-18}$ Patients with REM sleep behavior disorder also show this cognitive profile, and these patients can evolve into DLB. ${ }^{19,20}$ The development of criteria for PDD and advancement of our understanding of the overlap between PDD and DLB will improve our ability to conduct clinical trials in these disorders. There is hope that neuro-psychological measures or biomarkers may allow the separation of subjects with coexistent Alzheimer pathology, who are less likely to meet criteria for DLB,${ }^{21}$ and might respond differently to medications.

Although the recent practice parameters indicate that the Mini-Mental State Examination (MMSE) and the Cambridge Cognitive Examination may be useful for screening for dementia in $\mathrm{PD},{ }^{8}$ assessment instruments incorporate executive function (Delis-Kaplan Executive Function System (DKEFS), ${ }^{22}$ Repeatable Battery for Assessment of Neuro-psychological Status, ${ }^{23}$ Dementia Rating Scale, ${ }^{24}$ Wechsler Adult Intelligence Scale - Revised Neuropsychological Instrument, ${ }^{25}$ Scales for Outcomes of Parkinson's disease-cognition ${ }^{26)}$ would be logical cognitive outcome measures in studies of PDD and DLB if they can be shown to be responsive to treatment. Specific tests or instruments that target assessment of executive function might be used if that is a target group of symptoms. ${ }^{27}$ Measurement of attention is another critical factor, given that it is part of the core criteria for DLB, and is evident in PDD. Computerized cognitive batteries that have been used in clinical trials of DLB and PDD, 
may be useful for monitoring fluctuating attention. ${ }^{28}$ Similar tests of reaction time have been used to discriminate demented from non-demented PD patients. ${ }^{29}$ Several valid questionnairebased approaches to measuring fluctuations should be considered for use in trials of PDD and DLB. ${ }^{30,31}$

\section{Non-Cognitive Targets}

Functional status (the ability to carry out daily activities) is an important outcome, reflecting caregiver burden. It is determined by cognitive, motor and behavioral features. Scales that reflect executive dysfunction would ideally be used in clinical trials. The Disability Assessment in Dementia scale is one such instrument. ${ }^{32}$ In addition to executive function, apathy and parkinsonism also contribute to functional impairment. In applying ADL instruments it is important to distinguish between ADLs that are not performed due to cognitive or behavioral difficulties from those that are not performed because of physical problems (since each necessitate different treatment approaches). In practice, caregivers are asked to judge if the patient can't perform a task because of cognitive problems as opposed to physical impairment; however, such judgments remain imperfect. In the published trial of rivastigmine in PDD the Alzheimer Disease Co-operative Studies Unit - ADL instrument was used in parallel with measures of cognition, behavior and motor function. ${ }^{33,34}$ Clearly, further study of the relationship of ADLs to other domains affected in dementia is important.

Behavioral symptoms are overlapping between DLB and PDD. ${ }^{35}$ Psychiatric symptoms including psychosis (hallucinations and delusions), depression and anxiety can be distressing to patients and family members. ${ }^{36}$ Depression and apathy are distinct phenomena that can confound and contribute to cognitive dysfunction. ${ }^{37-40}$ Behavioral problems such as agitation are difficult to manage and can trigger nursing home placement. The Neuropychiatric Inventory (NPI $)^{41}$ has been used to measure behavior problems in $\mathrm{DLB}^{42}$ and has been sensitive to change in clinical trials of patients with dementia. ${ }^{43}$ Specific measures with a wider range of responses should be included in trials in which specific target symptoms are relevant; however, most scales have not been validated in DLB or PDD. ${ }^{8}$ This may necessitate using scales that have been used in other dementias, such as the Cornell Depression Rating Scale, ${ }^{44}$ or the development of new instruments for specific target symptoms. ${ }^{45}$

\section{Neurochemical Basis for Treatment}

Although the prominent pathologic change in PDD and DLB is alpha-synuclein positive Lewy bodies, there is a suggestion that amyloid, tau and synuclein pathology may be synergistic, raising the possibility that treatments aimed at affecting these abnormal proteins in one disease may be helpful in others. ${ }^{46}$ Dopaminergic, cholinergic, noradrenergic, serotonergic and glutaminergic systems may all be affected in Lewy body-related dementias. ${ }^{47}$ The impact of dopaminergic therapy on cognition in these disorders is not yet well established. Open-label, small placebo-controlled studies but few large scale studies have examined cholinesterase inhibitors in PDD and DLB. Rivastigmine, a cholinesterase inhibitor was effective in single large placebo-controlled trials in DLB and in PDD. ${ }^{34,43}$

\section{BIOMARKERS}

There are no established biomarkers in Lewy body disorders with dementia. Volumetric magnetic resonance brain imaging studies have shown atrophy for both PDD and DLB, generally to a lesser degree than in AD, in medial temporal, frontal, occipital, and parietal lobes as well as in sub-cortical structures. ${ }^{48-53}$ Progressive brain atrophy has been reported. ${ }^{54}$ Magnetic resonance spectroscopy has shown decreased $\mathrm{N}$ acetylaspartate/creatine (NAA/Cr) and normal myolnositol/ creatine (mI/Cr) (in contrast to AD) in Parkinson's disease. ${ }^{55-57}$ Blood flow (SPECT) and metabolic (PET) studies have shown cerebral dysfunction in Lewy body dementias. ${ }^{58,59}$ Findings examining dopaminergic terminals using PET and SPECT show decreased striatal binding, distinct from AD. ${ }^{60-63}$ Cholinergic changes have been shown in PDD and DLB using PET. ${ }^{64}$ Cerebrospinal fluid changes in DLB may be distinct from those in $\mathrm{AD} .{ }^{65}$ As with the neuropsychological studies, there are few direct comparisons between PDD and DLB, but imaging and cerebrospinal fluid biomarkers may hold promise for future clinical trials for defining patient groups, and potentially for tracking the course of disease. Currently no method has been validated for longitudinal assessment in PDD and DLB as a surrogate marker; however, dopamine transporter imaging, and possibly 123I-metaiodobenzylguanidine (MIBG) cardiac scans (which indicates post-ganglionic cardiac sympathetic denervation $)^{66}$ can be used to assist in distinguishing these primary Lewy body dementias from AD.

\section{Clinical Trials in PDD and DLB}

\section{Cholinesterase Inhibitors and Cholinergic Agents}

One of the important consequences of defining DLB was the development of clinical trials. Initial case series were encouraging with the cholinesterase inhibitors donepezil, ${ }^{67-71}$ rivastigmine, ${ }^{72-74}$ and galantamine. ${ }^{75,76}$ A Cochrane Review identified one placebo controlled trial showing modest efficacy. ${ }^{43,77}$ Subgroups of patients may be more likely to benefit from therapy. ${ }^{78,79}$

Until recently, most published trials in Parkinson's disease with dementia have been open label, ${ }^{80,81}$ except small studies of donepezil. ${ }^{82-84}$ Withdrawal of medication led to deterioration in a series of patients with PDD and DLB treated with donepezil. ${ }^{85}$ A recent study suggested that the response of DLB and PDD to donepezil was similar. ${ }^{86}$ Rivastigmine was associated with marked deterioration in a case study, ${ }^{87}$ but this might be a class effect, not restricted to a specific agent. ${ }^{88}$ A large placebocontrolled study of rivastigmine was recently reported with positive results, consistent with smaller open label studies. ${ }^{34,89,90}$ Hallucinations may be prone to improvement. ${ }^{91,92}$ Attention was particularly improved in a secondary analysis from the large placebo controlled of rivastigmine. ${ }^{93}$ Improvement of dementia in PDD with rivastigmine appears to be sustained in patients who were able to tolerate an open-label extension. ${ }^{94}$ One open label study of galantamine in PDD has been reported. ${ }^{95}$ While cholinesterase inhibitors remain promising, confirmatory studies, and trials of different medications, which may differ in their efficacy in DLB and PDD will be needed, as suggested in a recent systematic review. ${ }^{96}$ Cholinergic agonists may also hold promise, but little data is available. 


\section{Anti-psychotic Agents}

A clinical feature highlighting the distinction between DLB and other dementias is marked sensitivity to typical antipsychotic medications. ${ }^{97}$ This has led to important practice changes, including the avoidance of typical anti-psychotics in these patients. Psychotic symptoms are also associated with poor outcomes in PD. Clozapine, an atypical antipsychotic drug, has been evaluated in Parkinson's disease in placebo-controlled trials, with two trials of PD, whose spectrum includes mildly impaired PDD patients, suggesting efficacy. ${ }^{98-101}$ Olanzapine has been shown to worsen motor function in placebo-controlled studies, including one comparing olanzapine to clozapine. ${ }^{102,103}$ Recent studies have compared anti-psychotic agents, providing a plausible model for studies in the frail population of patients with psychosis. ${ }^{104,105}$ Atypical neuroleptics may increase cardiovascular risk and events as well as mortality. ${ }^{106,107}$ These concerns need to be considered in off-label use and in devising future clinical trials. In trials, risk factors and vascular events need to be specifically addressed in informed consent and carefully monitored.

Agents such as quetiapine ${ }^{108-110}$ aripiprazole $^{111}$ and ziprasidone, have generally been studied in open label series or case reports to date. Experience with olanzapine, where open label studies were encouraging, but placebo-controlled studies showed side-effects, highlight the importance of controlled trials. A small placebo-controlled trial of quetiapine indicated that the drug did not worsen parkinsonism, but was ineffective. ${ }^{112}$ Given the frailty of patients with psychosis, it may be difficult to contemplate withholding treatment; however, given that usual care may be as effective as medication, placebo-controlled studies are still warranted. The response of patients with DLB may or may not differ from PDD. ${ }^{113}$

\section{Dopaminergic Medications}

Since motor impairment is significant in patients with PDD and in some patients with DLB, studies targeting its treatment are relevant. One study has shown that patients with PDD and DLB respond to dopaminergic therapy to a lesser degree than patients without dementia. ${ }^{14}$ A lower percentage of DLB patients compared to PDD patients responded to levodopa in another recent study. ${ }^{115}$ Studies examining treatment of motor problems in advanced PD should include cognitive outcome measures.

\section{Other Symptomatic Approaches}

Noradrenergic or serotonergic systems may be involved in DLB and PDD and offer potential therapeutic approaches. Antiglutaminergic medications merit consideration in light of studies that suggest that such drugs may confer cognitive benefit in Alzheimer disease, ${ }^{116,117}$ given that they might improve motor function of PD, and have the potential for neuroprotection. Recent open-label reports of memantine in DLB have had mixed results including case reports of exacerbation of symptoms ${ }^{118}$ and a case-series showing that the memantine can be tolerated. ${ }^{119}$

\section{Disease Modifying Therapies}

Disease modifying therapies, which are under active investigation in $\mathrm{PD}^{120}$ and $\mathrm{AD}^{121}$ may be applicable to DLB and
PDD. While distinct animal models for DLB and PDD that can be used to understand their pathophysiology and develop new therapies are not as advanced as in PD and AD they are likely be developed. Clearly future trials in Lewy-body related dementias will have to consider agents with disease modifying potential, which will necessitate specific design considerations ${ }^{122}$ While many of the outcome measures may be similar to those of studies of symptomatic benefit, randomized start or randomized withdrawal designs, where patients are initiated or discontinued from medication in a blinded fashion, are approaches to deal with the potential for symptomatic benefit. A recent randomized start design suggested disease modifying benefits of rasagaline in PD. ${ }^{123}$ Longer studies are likely to be necessary, given the slowly progressive nature of neurodegeneration. Moreover, in the long term, outcomes such as survival with good function, and quality of life will be paramount.

\section{Choice of Outcome Measures}

While outcome measures chosen for clinical trials are based on the signs and symptoms that are being targeted by the intervention, it is clear that PDD and DLB are multi-dimensional disorders and clinical trials will generally include cognitive, behavioral, functional and other measures. To date no surrogate measure is relevant. In addition to the specific instruments chosen, the disease stage of the patients is also an important factor because both contribute to the possibility of ceiling effect, where patients score so well on a test and have minimal room for improvement, and floor effect where patients score so poorly that they may not be able to decline. Recent large placeo-controlled trials of rivastigmine in $\mathrm{DLB}^{43}$ and $\mathrm{PDD}^{34}$ provide some guidance for mild to moderate stage patients (MMSE scores of 10 or higher; maximum score of 24 in the PDD study) and give some idea of the treatment effects that can be observed with various measures. Cohen's effect sizes (d) is the difference in means of two groups divided by their standard deviation: $\mathrm{d}$ of 0.2 is small; 0.5 is medium; 0.8 is large. In DLB data are available for the MMSE, with an estimated d of 0.37, and the NPI-10 item, with $\mathrm{d}$ of $0.26{ }^{43} \mathrm{By}$ comparison in the PDD study, $\mathrm{d}$ for the MMSE was 0.26 , and for the NPI-10 was $0.17 .{ }^{34}$ In the latter trial, other measures had similarly small effect sizes: Alzheimer's disease assessment scale - cognitive (ADAS-cog), 0.28; Clinical global impression of change (CGIC), 0.34; Alzheimer's disease cooperative studies unit ADL (ADCSADL), 0.14; DKEFS, 0.30; clock drawing, 0.29; reaction time, 0.17 . Fluctuation in level of arousal, characteristic of DLB and PDD, makes it difficult to assess true effects and may contribute to variability in test performance, thereby reducing apparent treatment effects.

\section{Clinical Trial Design Considerations (Table 3)}

Non-randomized and open label studies only provide a basis for planning randomized trials and cannot form the basis for treatment choices. The gold standard of clinical trials remains the parallel-group randomized double blind placebo-controlled design. If there are no accepted treatments it remains ethical to consider a placebo arm. Given the potential to worsen patients, stopping rules, which incorporate assessment of futility of continuing a trial, and careful safety monitoring should be built into clinical trials. When treatments are available, comparison 
Table 3: Potential study designs: pros and cons

Open label

Without/with controls

Little historical control data to be able to use this approach

Crossover

Permanent no-reversible improvements

Parallel group

2 arms (active treatment versus placebo)

3 arms (two active, one placebo)

Dose response

Factorial designs

Superiority/inferiority

Equivalency trials

Randomized start/stopping

Can look at neuroprotection

Can assess if effects are sustained

studies with the goal of assessing equivalency, inferiority or superiority can be considered. Generally these studies require larger sample sizes than placebo-controlled studies. Fluctuating or transitory symptoms make cross-over studies (where patients act as their on controls) difficult to interpret in general. A major challenge in all dementia studies is to obtain a representative sample of subjects. These concerns are highlighted by data that patients with Alzheimer disease in clinical trials are not representative of the overall patient population and that studies of Parkinson's disease have excluded elderly subjects. ${ }^{124,125}$ Nevertheless, subgroups of patients might be targeted for intervention. For example, executive dysfunction, attention impairment and fluctuations, depression, apathy, and psychosis are specific disturbing symptoms that might be specifically studied. A global assessment of change should be included as an outcome measure. For the present PDD and DLB should be considered distinct entities. In the future, clinical trials aimed at common problems might include patients with both PDD and $\mathrm{DLB}$, but if that is done, pre-planned stratification would have to be done from the start to allow assessment of potential differential treatment response. Ethical concerns are paramount in all clinical research. Patients with DLB and PDD may have difficulty with comprehending treatment options, highlighting the importance of establishing surrogate decision makers early in the course of disease and taking extreme care in obtaining informed consent. ${ }^{126}$

\section{Conclusions and Recommendations}

Clinical trials for PDD and DLB are in their early stages compared to studies in AD and those for the motor aspects of PD.
In part this is related to barriers that can be overcome with additional research (Table 4). Defining these entities and their natural history remain important ongoing issues. Natural history studies would ideally be population based and with autopsy confirmation. Separating patients with coexistent AD may be important for future trials, and may be possible using biomarkers. Cognitive outcome measures designed for AD may not be ideal for PDD and DLB in that they emphasize memory and not frontal/executive measures. Measures which are valid in the setting of PDD/DLB need to be developed. Non-cognitive measures are also important targets. Biomarkers in PDD and DLB are critically needed, both to monitor change in clinical trials and to exclude coexistent pathologies. Clearly motor function and its progression must be taken into account in these disorders. Conversely, studies in advanced Parkinson's disease that target motor symptoms should also assess cognitive function.

\section{ACKNOWLEDGEMENTS}

We thank Sheri Foster for assisting with manuscript preparation.

\section{Table 4: Critical barriers to clinical trials in Parkinson's disease with dementia and Dementia with Lewy bodies and recommendations}

1. Lack of consensus definition for Parkinson's disease with dementia

2. Inaccuracies in diagnosis of DLB, especially in cases with overlapping pathology

3. Overlapping pathology (Cortical and subcortical Lewy bodies, amyloid plaques, neurofibrillary tangles, cerebral infarctions, white matter disease)

a. Pathophysiology of dementia is not fully established

4. Subgroups of patients within disease groups who may have treatment response

a. Cognitive: amnestic, executive dysfunction, multiple cognitive

domains

b. Fluctuating

c. Psychotic, hallucinating

d. Apathetic, depressed

5. Natural history of cognitive impairment in PD is not fully defined

6. Assessments instruments available for clinical trials have been designed for Alzheimer disease, specific challenges include

a. Longitudinal measurement of executive function

b. Measurement of attention and fluctuations

c. Activities of daily living instruments with executive components

7. Imaging/other biomarker correlates of dementia in PDD and DLB are not established (surrogate measures are lacking)

8. Most studies in advanced PD target motor symptoms only

9. Motor impairment confounds cognitive and functional assessments 


\section{DEClaration}

In the past two years Richard Camicioli has been on an advisory board or a speaker for Glaxo-Smith-Kline, JanssenOrtho, Pfizer Canada, and participated in clinical trials sponsored or co-sponsored by Cephalon, Janssen-Ortho, Novartis, Schwartz Pharma and Teva Pharmaceuticals, and has received an unrestricted research grant from Pfizer Canada for an investigator initiated study. In the past two years Serge Gauthier has been an advisor/consultant or speaker for Glaxo-SmithKline, Jannsen Ortho, Lundbeck, Myriad, Neurochem, Novartis, Pfizer, Sanofi, Servier, participated in clinical trials sponsored by Janssen-Ortho, Lundbeck, Neurochem, Pfizer.

\section{REFERENCES}

1. Camicioli R, Fisher N. Progress in clinical neurosciences: Parkinson's disease with dementia and dementia with Lewy bodies. Can J Neurol Sci. 2004; 31 (1):7-21.

2. McKeith IG, Galasko D, Kosaka K, Perry EK, Dickson DW, Hansen LA, et al. Consensus guidelines for the clinical and pathologic diagnosis of dementia with Lewy bodies (DLB): report of the consortium on DLB international workshop. Neurology. 1996; 47 (5):1113-24

3. McKeith IG, Dickson DW, Lowe J, Emre M, O'Brien JT, Feldman $\mathrm{H}$, et al. Diagnosis and management of dementia with Lewy bodies: third report of the DLB Consortium. Neurology. 2005; 65 (12):1863-72.

4. Tiraboschi P, Salmon DP, Hansen LA, Hofstetter RC, Thal LJ, Corey-Bloom J. What best differentiates Lewy body from Alzheimer's disease in early-stage dementia? Brain. 2006; 129 (Pt 3):729-35.

5. American Psychiatric Association; Diagnostic and statistical manual of mental disorders: DSM-IV. 4th ed. Washington, DC: American Psychiatric Association; 1994.

6. Burn DJ, Rowan EN, Minett T, Sanders J, Myint P, Richardson J, et al. Extrapyramidal features in Parkinson's disease with and without dementia and dementia with Lewy bodies: a crosssectional comparative study. Mov Disord. 2003; 18 (8):884-9.

7. Boeve BF, Silber MH, Parisi JE, Dickson DW, Ferman TJ, Benarroch EE, et al. Synucleinopathy pathology and REM sleep behavior disorder plus dementia or parkinsonism. Neurology. 2003; 61 (1):40-5.

8. Miyasaki JM, Shannon K, Voon V, Ravina B, Kleiner-Fisman G, Anderson K, et al. Practice parameter: evaluation and treatment of depression, psychosis, and dementia in Parkinson disease (an evidence-based review). Report of the Quality Standards Subcommittee of the American Academy of Neurology. Neurology. 2006; 66 (7):996-1002.

9. Stern Y, Tang MX, Jacobs DM, Sano M, Marder K, Bell K, et al. Prospective comparative study of the evolution of probable Alzheimer's disease and Parkinson's disease dementia. J Int Neuropsychol Soc. 1998; 4 (3):279-84

10. Noe E, Marder K, Bell KL, Jacobs DM, Manly JJ, Stern Y. Comparison of dementia with Lewy bodies to Alzheimer's disease and Parkinson's disease with dementia. Mov Disord. 2004; 19 (1):60-7.

11. Hamilton JM, Salmon DP, Galasko D, Delis DC, Hansen LA, Masliah E, et al. A comparison of episodic memory deficits in neuropathologically-confirmed Dementia with Lewy bodies and Alzheimer's disease. J Int Neuropsychol Soc. 2004; 10 (5):689-97.

12. Simard M, van Reekum R, Myran D, Panisset M, Cohen T, Freedman M, et al. Differential memory impairment in dementia with Lewy bodies and Alzheimer's disease. Brain Cogn. 2002; 49 (2):244-9.

13. Collerton D, Burn D, McKeith I, O'Brien J. Systematic review and meta-analysis show that dementia with Lewy bodies is a visualperceptual and attentional-executive dementia. Dement Geriatr Cogn Disord. 2003; 16 (4):229-37.
14. Lambon RMA, Powell J, Howard D, Whitworth AB, Garrard P, Hodges JR. Semantic memory is impaired in both dementia with Lewy bodies and dementia of Alzheimer's type: a comparative neuropsychological study and literature review. J Neurol Neurosurg Psychiatry. 2001; 70 (2):149-56.

15. Davis HS, Rockwood K. Conceptualization of mild cognitive impairment: a review. Int J Geriatr Psychiatry. 2004; 19 (4): 313-9.

16. Cormack F, Aarsland D, Ballard C, Tovee MJ. Pentagon drawing and neuropsychological performance in Dementia with Lewy bodies, Alzheimer's disease, Parkinson's disease and Parkinson's disease with dementia. Int J Geriatr Psychiatry. 2004; 19 (4): 371-7.

17. Ballard CG, Aarsland D, McKeith I, O'Brien J, Gray A, Cormack F, et al. Fluctuations in attention: PD dementia vs DLB with parkinsonism. Neurology. 2002; 59 (11):1714-20.

18. Downes JJ, Priestley NM, Doran M, Ferran J, Ghadiali E, Cooper P. Intellectual, mnemonic, and frontal functions in dementia with Lewy bodies: a comparison with early and advanced Parkinson's disease. Behav Neurol. 1998; 11 (3):173-83.

19. Boeve BF, Silber MH, Ferman TJ, Lucas JA, Parisi JE. Association of REM sleep behavior disorder and neurodegenerative disease may reflect an underlying synucleinopathy. Mov Disord. 2001; 16 (4):622-30.

20. Boeve BF, Silber MH, Ferman TJ. REM sleep behavior disorder in Parkinson's disease and dementia with Lewy bodies. J Geriatr Psychiatry Neurol. 2004; 17 (3):146-57.

21. Merdes AR, Hansen LA, Jeste DV, Galasko D, Hofstetter CR, Ho GJ, et al. Influence of Alzheimer pathology on clinical diagnostic accuracy in dementia with Lewy bodies. Neurology. 2003; 60 (10): $1586-90$.

22. Delis DC, Kramer JH, Kaplan E, Holdnack J. Reliability and validity of the Delis-Kaplan executive function system: an update. J Int Neuropsychol Soc. 2004; 10 (2):301-3.

23. Beatty WW, Ryder KA, Gontkovsky ST, Scott JG, McSwan KL, Bharucha KJ. Analyzing the subcortical dementia syndrome of Parkinson's disease using the RBANS. Arch Clin Neuropsychol. 2003; 18 (5):509-20.

24. Brown GG, Rahill AA, Gorell JM, McDonald C, Brown SJ, Sillanpaa $\mathrm{M}$, et al. Validity of the Dementia rating scale in assessing cognitive function in Parkinson's disease. J Geriatr Psychiatry Neurol. 1999; 12 (4):180-8.

25. Peavy GM, Salmon D, Bear PI, Paulsen JS, Cahn DA, Hofstetter $\mathrm{CR}$, et al. Detection of mild cognitive deficits in Parkinson's disease patients with the WAIS-R NI. J Int Neuropsychol Soc. 2001; 7 (5):535-43.

26. Marinus J, Visser M, Verwey NA, Verhey FR, Middelkoop HA, Stiggelbout AM, et al. Assessment of cognition in Parkinson's disease. Neurology. 2003; 61 (9):1222-8.

27. Royall DR, Lauterbach EC, Cummings JL, Reeve A, Rummans TA, Kaufer DI, et al. Executive control function: a review of its promise and challenges for clinical research. A report from the Committee on Research of the American Neuropsychiatric Association. J Neuropsychiatry Clin Neurosci. 2002; 14 (4): 377-405.

28. Wesnes KA, McKeith IG, Ferrara R, Emre M, Del Ser T, Spano PF, et al. Effects of rivastigmine on cognitive function in dementia with Lewy bodies: a randomized placebo-controlled international study using the cognitive drug research computerised assessment system. Dement Geriatr Cogn Disord. 2002; 13 (3):183-92.

29. Pate DS, Margolin DI. Cognitive slowing in Parkinson's and Alzheimer's patients: distinguishing bradyphrenia from dementia. Neurology. 1994; 44 (4):669-74.

30. Bradshaw J, Saling M, Hopwood M, Anderson V, Brodtmann A. Fluctuating cognition in dementia with Lewy bodies and Alzheimer's disease is qualitatively distinct. J Neurol Neurosurg Psychiatry. 2004; 75 (3):382-7.

31. Ferman TJ, Smith GE, Boeve BF, Ivnik RJ, Petersen RC, Knopman $\mathrm{D}$, et al. DLB fluctuations: specific features that reliably differentiate DLB from AD and normal aging. Neurology. 2004; $62(2): 181-7$. 
32. Gelinas I, Gauthier L, McIntyre M, Gauthier S. Development of a functional measure for persons with Alzheimer's disease: the disability assessment for dementia. Am J Occup Ther. 1999; 53 (5):471-81.

33. Galasko D, Bennett D, Sano M, Ernesto C, Thomas R, Grundman $\mathrm{M}$, et al. An inventory to assess activities of daily living for clinical trials in Alzheimer's disease. The Alzheimer's Disease Cooperative Study. Alzheimer Dis Assoc Disord. 1997; 11 Suppl 2:S33-9

34. Emre M, Aarsland D, Albanese A, Byrne EJ, Deuschl G, De Deyn PP, et al. Rivastigmine for dementia associated with Parkinson's disease. N Engl J Med. 2004; 351 (24):2509-18.

35. Aarsland D, Ballard C, Larsen JP, McKeith I. A comparative study of psychiatric symptoms in dementia with Lewy bodies and Parkinson's disease with and without dementia. Int J Geriatr Psychiatry. 2001; 16 (5):528-36.

36. Weintraub D, Moberg PJ, Duda JE, Katz IR, Stern MB. Effect of psychiatric and other nonmotor symptoms on disability in Parkinson's disease. J Am Geriatr Soc. 2004; 52 (5):784-8.

37. Norman S, Troster AI, Fields JA, Brooks R. Effects of depression and Parkinson's disease on cognitive functioning. J Neuropsychiatry Clin Neurosci. 2002; 14 (1):31-6.

38. Cubo E, Bernard B, Leurgans S, Raman R. Cognitive and motor function in patients with Parkinson's disease with and without depression. Clin Neuropharmacol. 2000; 23 (6):331-4.

39. Pluck GC, Brown RG. Apathy in Parkinson's disease. J Neurol Neurosurg Psychiatry. 2002; 73 (6):636-42.

40. Isella V, Melzi P, Grimaldi M, Iurlaro S, Piolti R, Ferrarese C, et al. Clinical, neuropsychological, and morphometric correlates of apathy in Parkinson's disease. Mov Disord. 2002; 17 (2):366-71.

41. Cummings JL, Mega M, Gray K, Rosenberg-Thompson S, Carusi DA, Gornbein J. The Neuropsychiatric Inventory: comprehensive assessment of psychopathology in dementia. Neurology. 1994; 44 (12):2308-14

42. Del Ser T, McKeith I, Anand R, Cicin-Sain A, Ferrara R, Spiegel R. Dementia with Lewy bodies: findings from an international multicentre study. Int J Geriatr Psychiatry. 2000; 15 (11): 1034-45.

43. McKeith I, Del Ser T, Spano P, Emre M, Wesnes K, Anand R, et al. Efficacy of rivastigmine in dementia with Lewy bodies: a randomized, double-blind, placebo-controlled international study. Lancet. 2000; 356 (9247):2031-6.

44. Alexopoulos GS, Abrams RC, Young RC, Shamoian CA. Cornell scale for depression in Dementia. Biol Psychiatry. 1988; 23 (3):271-84.

45. Robert PH, Clairet S, Benoit M, Koutaich J, Bertogliati C, Tible O, et al. The apathy inventory: assessment of apathy and awareness in Alzheimer's disease, Parkinson's disease and mild cognitive impairment. Int J Geriatr Psychiatry. 2002; 17 (12):1099-105.

46. Lee VM, Giasson BI, Trojanowski JQ. More than just two peas in a pod: common amyloidogenic properties of tau and alphasynuclein in neurodegenerative diseases. Trends Neurosci. 2004; 27 (3):129-34.

47. Perry EK, McKeith I, Thompson P, Marshall E, Kerwin J, Jabeen S, et al. Topography, extent, and clinical relevance of neurochemical deficits in dementia of Lewy body type, Parkinson's disease, and Alzheimer's disease. Ann N Y Acad Sci. 1991; 640:197-202.

48. Burton EJ, McKeith IG, Burn DJ, Williams ED, O'Brien JT. Cerebral atrophy in Parkinson's disease with and without dementia: a comparison with Alzheimer's disease, dementia with Lewy bodies and controls. Brain. 2004; 127 (Pt 4):791-800.

49. Camicioli R, Moore MM, Kinney A, Corbridge E, Glassberg K, Kaye JA. Parkinson's disease is associated with hippocampal atrophy. Mov Disord. 2003; 18 (7):784-90.

50. Cousins DA, Burton EJ, Burn D, Gholkar A, McKeith IG, O'Brien JT. Atrophy of the putamen in dementia with Lewy bodies but not Alzheimer's disease: an MRI study. Neurology. 2003; 61 (9):1191-5.

51. Almeida OP, Burton EJ, McKeith I, Gholkar A, Burn D, O'Brien JT. MRI study of caudate nucleus volume in Parkinson's disease with and without dementia with Lewy bodies and Alzheimer's disease. Dement Geriatr Cogn Disord. 2003; 16 (2):57-63.
52. Middelkoop HA, van der Flier WM, Burton EJ, Lloyd AJ, Paling S, Barber R, et al. Dementia with Lewy bodies and AD are not associated with occipital lobe atrophy on MRI. Neurology. 2001; 57 (11):2117-20.

53. Barber R, McKeith I, Ballard C, O'Brien J. Volumetric MRI study of the caudate nucleus in patients with dementia with Lewy bodies, Alzheimer's disease, and vascular dementia. J Neurol Neurosurg Psychiatry. 2002; 72 (3):406-7.

54. O'Brien JT, Paling S, Barber R, Williams ED, Ballard C, McKeith IG, et al. Progressive brain atrophy on serial MRI in dementia with Lewy bodies, AD, and vascular dementia. Neurology. 2001; 56 (10): $1386-8$

55. Molina JA, Garcia-Segura JM, Benito-Leon J, Gomez-Escalonilla C, del Ser T, Martinez V, et al. Proton magnetic resonance spectroscopy in dementia with Lewy bodies. Eur Neurol. 2002; 48 (3):158-63.

56. Summerfield C, Gomez-Anson B, Tolosa E, Mercader JM, Marti MJ, Pastor P, et al. Dementia in Parkinson disease: a proton magnetic resonance spectroscopy study. Arch Neurol. 2002; 59 (9): 1415-20.

57. Camicioli RM, Korzan JR, Foster SL, Fisher NJ, Emery DJ, Bastos $\mathrm{AC}$, et al. Posterior cingulate metabolic changes occur in Parkinson's disease patients without dementia. Neurosci Lett. 2004; 354 (3):177-80.

58. Firbank MJ, Colloby SJ, Burn DJ, McKeith IG, O'Brien JT. Regional cerebral blood flow in Parkinson's disease with and without dementia. Neuroimage. 2003; 20 (2):1309-19.

59. Colloby S, O'Brien J. Functional imaging in Parkinson's disease and dementia with Lewy bodies. J Geriatr Psychiatry Neurol. 2004; 17 (3): 158-63.

60. Gilman S, Koeppe RA, Little R, An H, Junck L, Giordani B, et al. Striatal monoamine terminals in Lewy body dementia and Alzheimer's disease. Ann Neurol. 2004; 55 (6):774-80.

61. Plotkin M, Amthauer H, Klaffke S, Kuhn A, Ludemann L, Arnold G, et al. Combined (123)I-FP-CIT and (123)I-IBZM SPECT for the diagnosis of parkinsonian syndromes: study on 72 patients. J Neural Transm. 2005;112(5):677-92.

62. O'Brien JT, Colloby S, Fenwick J, Williams ED, Firbank M, Burn $\mathrm{D}$, et al. Dopamine transporter loss visualized with FP-CIT SPECT in the differential diagnosis of dementia with Lewy bodies. Arch Neurol. 2004; 61 (6):919-25.

63. Walker Z, Costa DC, Walker RW, Lee L, Livingston G, Jaros E, et al. Striatal dopamine transporter in dementia with Lewy bodies and Parkinson disease: a comparison. Neurology. 2004; 62 (9):1568-72

64. Bohnen NI, Kaufer DI, Ivanco LS, Lopresti B, Koeppe RA, Davis JG, et al. Cortical cholinergic function is more severely affected in parkinsonian dementia than in Alzheimer disease: an in vivo positron emission tomographic study. Arch Neurol. 2003; 60 (12): $1745-8$.

65. Gomez-Tortosa E, Gonzalo I, Fanjul S, Sainz MJ, Cantarero S, Cemillan $\mathrm{C}$, et al. Cerebrospinal fluid markers in dementia with Lewy bodies compared with Alzheimer disease. Arch Neurol. 2003; 60 (9):1218-22.

66. Hanyu H, Shimizu S, Hirao K, Kanetaka H, Iwamoto T, Chikamori $\mathrm{T}$, et al. Comparative value of brain perfusion SPECT and [(123)I]MIBG myocardial scintigraphy in distinguishing between dementia with Lewy bodies and Alzheimer's disease. Eur J Nucl Med Mol Imaging. 2006; 33 (3):248-53.

67. Kaufer DI, Catt KE, Lopez OL, DeKosky ST. Dementia with Lewy bodies: response of delirium-like features to donepezil. Neurology. 1998; 51 (5):1512.

68. Shea C, MacKnight C, Rockwood K. Donepezil for treatment of dementia with Lewy bodies: a case series of nine patients. Int Psychogeriatr. 1998; 10 (3):229-38.

69. Aarsland D, Bronnick K, Karlsen K. Donepezil for dementia with Lewy bodies: a case study. Int J Geriatr Psychiatry. 1999; 14 (1):69-72.

70. Samuel W, Caligiuri M, Galasko D, Lacro J, Marini M, McClure FS, et al. Better cognitive and psychopathologic response to donepezil in patients prospectively diagnosed as dementia with Lewy bodies: a preliminary study. Int J Geriatr Psychiatry. 2000; 15 (9):794-802. 
71. Querfurth HW, Allam GJ, Geffroy MA, Schiff HB, Kaplan RF. Acetylcholinesterase inhibition in dementia with Lewy bodies: results of a prospective pilot trial. Dement Geriatr Cogn Disord. 2000; 11 (6):314-21.

72. McKeith IG, Grace JB, Walker Z, Byrne EJ, Wilkinson D, Stevens $\mathrm{T}$, et al. Rivastigmine in the treatment of dementia with Lewy bodies: preliminary findings from an open trial. Int $\mathbf{J}$ Geriatr Psychiatry. 2000; 15 (5):387-92.

73. Grace J, Daniel S, Stevens T, Shankar KK, Walker Z, Byrne EJ, et al. Long-term use of rivastigmine in patients with dementia with Lewy bodies: an open-label trial. Int Psychogeriatr. 2001; 13 (2):199-205.

74. Maclean LE, Collins CC, Byrne EJ. Dementia with Lewy bodies treated with rivastigmine: effects on cognition, neuropsychiatric symptoms, and sleep. Int Psychogeriatr. 2001; 13 (3):277-88.

75. Edwards KR, Hershey L, Wray L, Bednarczyk EM, Lichter D, Farlow M, et al. Efficacy and safety of galantamine in patients with dementia with Lewy bodies: a 12-week interim analysis. Dement Geriatr Cogn Disord. 2004; 17 Suppl 1:S40-8.

76. Holm AC. Alleviation of multiple abnormalities by galantamine treatment in two patients with dementia with Lewy bodies. Am J Alzheimers Dis Other Demen. 2004; 19 (4):215-8.

77. Wild R, Pettit T, Burns A. Cholinesterase inhibitors for dementia with Lewy bodies. Cochrane Database Syst Rev 2003; (3):CD003672.

78. McKeith IG, Wesnes KA, Perry E, Ferrara R. Hallucinations predict attentional improvements with rivastigmine in dementia with Lewy bodies. Dement Geriatr Cogn Disord. 2004; 18 (1):94-100.

79. Pakrasi S, Mukaetova-Ladinska EB, McKeith IG, O'Brien JT. Clinical predictors of response to Acetyl Cholinesterase Inhibitors: experience from routine clinical use in Newcastle. Int J Geriatr Psychiatry. 2003; 18 (10):879-86.

80. Werber EA, Rabey JM. The beneficial effect of cholinesterase inhibitors on patients suffering from Parkinson's disease and dementia. J Neural Transm. 2001; 108 (11):1319-25.

81. Hutchinson M, Fazzini E. Cholinesterase inhibition in Parkinson's disease. J Neurol Neurosurg Psychiatry. 1996; 61 (3):324-5.

82. Aarsland D, Litvan I, Salmon D, Galasko D, Wentzel-Larsen T, Larsen JP. Performance on the dementia rating scale in Parkinson's disease with dementia and dementia with Lewy bodies: comparison with progressive supranuclear palsy and Alzheimer's disease. J Neurol Neurosurg Psychiatry. 2003; 74 (9): 1215-20.

83. Leroi I, Brandt J, Reich SG, Lyketsos CG, Grill S, Thompson R, et al. Randomized placebo-controlled trial of donepezil in cognitive impairment in Parkinson's disease. Int J Geriatr Psychiatry. 2004; $19(1): 1-8$

84. Ravina B, Putt M, Siderowf A, Farrar JT, Gillespie M, Crawley A, et al. Donepezil for dementia in Parkinson's disease: a randomized, double blind, placebo controlled, crossover study. J Neurol Neurosurg Psychiatry. 2005; 76 (7):934-9.

85. Minett TS, Thomas A, Wilkinson LM, Daniel SL, Sanders J, Richardson J, et al. What happens when donepezil is suddenly withdrawn? An open label trial in dementia with Lewy bodies and Parkinson's disease with dementia. Int J Geriatr Psychiatry. 2003; 18 (11):988-93.

86. Thomas AJ, Burn DJ, Rowan EN, Littlewood E, Newby J, Cousins $\mathrm{D}$, et al. A comparison of the efficacy of donepezil in Parkinson's disease with dementia and dementia with Lewy bodies. Int $\mathbf{J}$ Geriatr Psychiatry. 2005; 20 (10):938-44.

87. Richard IH, Justus AW, Greig NH, Marshall F, Kurlan R. Worsening of motor function and mood in a patient with Parkinson's disease after pharmacologic challenge with oral rivastigmine. Clin Neuropharmacol. 2002; 25 (6):296-9.

88. Onofrj M, Thomas A. Severe worsening of parkinsonism in Lewy body dementia due to donepezil. Neurology 2003; 61 (10):1452.

89. Giladi N, Shabtai H, Gurevich T, Benbunan B, Anca M, Korczyn AD. Rivastigmine (Exelon) for dementia in patients with Parkinson's disease. Acta Neurol Scand. 2003; 108 (5):368-73.

90. Fogelson N, Kogan E, Korczyn AD, Giladi N, Shabtai H, Neufeld MY. Effects of rivastigmine on the quantitative EEG in demented Parkinsonian patients. Acta Neurol Scand. 2003; 107 (4):252-5.
91. Bullock R, Cameron A. Rivastigmine for the treatment of dementia and visual hallucinations associated with Parkinson's disease: a case series. Curr Med Res Opin. 2002; 18 (5):258-64.

92. Bergman J, Lerner V. Successful use of donepezil for the treatment of psychotic symptoms in patients with Parkinson's disease. Clin Neuropharmacol. 2002; 25 (2):107-10.

93. Wesnes KA, McKeith I, Edgar C, Emre M, Lane R. Benefits of rivastigmine on attention in dementia associated with Parkinson disease. Neurology. 2005; 65 (10):1654-6.

94. Poewe W, Wolters E, Emre M, Onofrj M, Hsu C, Tekin S, et al. Long-term benefits of rivastigmine in dementia associated with Parkinson's disease: an active treatment extension study. Mov Disord. 2006; 21 (4):456-61.

95. Aarsland D, Hutchinson M, Larsen JP. Cognitive, psychiatric and motor response to galantamine in Parkinson's disease with dementia. Int J Geriatr Psychiatry. 2003; 18 (10):937-41.

96. Maidment I, Fox C, Boustani M. Cholinesterase inhibitors for Parkinson's disease dementia. Cochrane Database Syst Rev. 2006; (1):CD004747.

97. Ballard C, Grace J, McKeith I, Holmes C. Neuroleptic sensitivity in dementia with Lewy bodies and Alzheimer's disease. Lancet. 1998; 351 (9108):1032-3.

98. The French Clozapine Parkinson Study Group. Clozapine in druginduced psychosis in Parkinson's disease. Lancet. 1999; 353 (9169):2041-2.

99. Pollak P, Tison F, Rascol O, Destee A, Pere JJ, Senard JM, et al. Clozapine in drug induced psychosis in Parkinson's disease: a randomised, placebo controlled study with open follow up. J Neurol Neurosurg Psychiatry. 2004; 75 (5):689-95.

100. The Parkinson Study Group. Low-dose clozapine for the treatment of drug-induced psychosis in Parkinson's disease. N Engl J Med. 1999; 340 (10):757-63.

101. Factor SA, Friedman JH, Lannon MC, Oakes D, Bourgeois K. Clozapine for the treatment of drug-induced psychosis in Parkinson's disease: results of the 12 week open label extension in the PSYCLOPS trial. Mov Disord. 2001; 16 (1):135-9.

102. Ondo WG, Levy JK, Vuong KD, Hunter C, Jankovic J. Olanzapine treatment for dopaminergic-induced hallucinations. Mov Disord. 2002; 17 (5):1031-5.

103. Breier A, Sutton VK, Feldman PD, Kadam DL, Ferchland I, Wright $\mathrm{P}$, et al. Olanzapine in the treatment of dopamimetic-induced psychosis in patients with Parkinson's disease. Biol Psychiatry. 2002; 52 (5):438-45.

104. Goetz CG, Blasucci LM, Leurgans S, Pappert EJ. Olanzapine and clozapine: comparative effects on motor function in hallucinating PD patients. Neurology. 2000; 55 (6):789-94.

105. Morgante L, Epifanio A, Spina E, Zappia M, Di Rosa AE, Marconi $\mathrm{R}$, et al. Quetiapine and clozapine in parkinsonian patients with dopaminergic psychosis. Clin Neuropharmacol. 2004; 27 (4):153-6.

106. Carson S, McDonagh MS, Peterson K. A systematic review of the efficacy and safety of atypical antipsychotics in patients with psychological and behavioral symptoms of dementia. J Am Geriatr Soc. 2006; 54 (2):354-61.

107. Schneider LS, Dagerman KS, Insel P. Risk of death with atypical antipsychotic drug treatment for dementia: meta-analysis of randomized placebo-controlled trials. JAMA. 2005; 294 (15):1934-43.

108. Juncos JL, Roberts VJ, Evatt ML, Jewart RD, Wood CD, Potter LS, et al. Quetiapine improves psychotic symptoms and cognition in Parkinson's disease. Mov Disord. 2004; 19 (1):29-35.

109. Targum SD, Abbott JL. Efficacy of quetiapine in Parkinson's patients with psychosis. J Clin Psychopharmacol. 2000; 20 (1):54-60.

110. Fernandez HH, Trieschmann ME, Burke MA, Jacques C, Friedman $\mathrm{JH}$. Long-term outcome of quetiapine use for psychosis among Parkinsonian patients. Mov Disord. 2003; 18 (5):510-4.

111. Fernandez HH, Trieschmann ME, Friedman JH. Aripiprazole for drug-induced psychosis in Parkinson disease: preliminary experience. Clin Neuropharmacol. 2004; 27 (1):4-5. 
112. Ondo WG, Tintner R, Dat Voung K, Lai D, Ringholz G. Doubleblind, placebo-controlled, unforced titration parallel trial of quetiapine for dopaminergic-induced hallucinations in Parkinson's disease. Mov Disord. 2005; 20(8):958-63.

113. Fernandez HH, Trieschmann ME, Burke MA, Friedman JH. Quetiapine for psychosis in Parkinson's disease versus dementia with Lewy bodies. J Clin Psychiatry. 2002; 63 (6):513-5.

114. Bonelli SB, Ransmayr G, Steffelbauer M, Lukas T, Lampl C, Deibl M. L-dopa responsiveness in dementia with Lewy bodies, Parkinson disease with and without dementia. Neurology. 2004; 63 (2):376-8.

115. Molloy S, McKeith IG, O'Brien JT, Burn DJ. The role of levodopa in the management of dementia with Lewy bodies. J Neurol Neurosurg Psychiatry. 2005; 76 (9):1200-3.

116. Reisberg B, Doody R, Stoffler A, Schmitt F, Ferris S, Mobius HJ. Memantine in moderate-to-severe Alzheimer's disease. N Engl J Med. 2003; 348 (14):1333-41.

117. Tariot PN, Farlow MR, Grossberg GT, Graham SM, McDonald S, Gergel I. Memantine treatment in patients with moderate to severe Alzheimer disease already receiving donepezil: a randomized controlled trial. JAMA. 2004; 291 (3):317-24.

118. Ridha BH, Josephs KA, Rossor MN. Delusions and hallucinations in dementia with Lewy bodies: worsening with memantine. Neurology. 2005; 65 (3):481-2.
119. Sabbagh MN, Hake AM, Ahmed S, Farlow MR. The use of memantine in dementia with Lewy bodies. J Alzheimers Dis. 2005; 7 (4):285-9.

120. Schapira AH. Disease modification in Parkinson's disease. Lancet. Neurol 2004; 3 (6):362-8.

121. Citron M. Strategies for disease modification in Alzheimer's disease. Nat Rev Neurosci. 2004; 5 (9):677-85.

122. Mani RB. The evaluation of disease modifying therapies in Alzheimer's disease: a regulatory viewpoint. Stat Med. 2004; 23 (2):305-14.

123. Parkinson Study Group. A controlled, randomized, delayed-start study of rasagiline in early Parkinson disease. Arch Neurol. 2004; 61 (4):561-6.

124. Schneider LS, Olin JT, Lyness SA, Chui HC. Eligibility of Alzheimer's disease clinic patients for clinical trials. J Am Geriatr Soc. 1997; 45 (8):923-8.

125. Mitchell SL, Sullivan EA, Lipsitz LA. Exclusion of elderly subjects from clinical trials for Parkinson disease. Arch Neurol. 1997; 54 (11):1393-8.

126. Dymek MP, Atchison P, Harrell L, Marson DC. Competency to consent to medical treatment in cognitively impaired patients with Parkinson's disease. Neurology. 2001; 56 (1):17-24. 